\title{
Chitin-Glucan Complex Production by Schizophyllum commune Submerged Cultivation
}

\author{
DZIANIS SMIRNOU*, MARTIN KRCMAR and EVA PROCHAZKOVA \\ CPN Ltd., Dolní Dobrouč, Czech Republic
}

Received 10 March 2011, revised 5 May 2011, accepted 15 June 2011

\begin{abstract}
Chitin-glucan complex is a fungal origin copolymer that finds application in medicine and cosmetics. Traditionally, the mycelium of Micromycetes is considered as an industrial chitin-glucan complex source. Basidiomycete Schizophyllum commune submerged cultivation for chitin-glucan complex production was studied. In different S. commune strains chitin-glucan complex composed $15.2 \pm 0.4$ to $30.2 \pm 0.2 \%$ of mycelium dry weight. Optimized conditions for chitin-glucan complex production (nutrient medium composition in g/l: sucrose -35 , yeast extract $-4, \mathrm{Na}_{2} \mathrm{HPO}_{4}{ }^{\star} 12 \mathrm{H}_{2} \mathrm{O}-2.5, \mathrm{MgSO}_{4}{ }^{*} 7 \mathrm{H}_{2} \mathrm{O}-0.5$; medium initial $\mathrm{pH} 6.5$; aeration intensity 21 of air per $11 \mathrm{of}$ medium; 144 hours of cultivation) resulted in $3.5 \pm 0.3 \mathrm{~g} / \mathrm{l}$ complex yield. Redirection of fungal metabolism from exopolysaccharide synthesis to chitin-glucan complex accumulation was achieved most efficiently by aeration intensity increase. Chitin-glucan complex from $S$. commune had the structure of microfibers with diameter $1-2 \mu \mathrm{m}$, had water-swelling capacity of $18 \mathrm{~g} / \mathrm{g}$, and was composed of $16.63 \%$ chitin and $83.37 \%$ glucan with a degree of chitin deacetylation of $26.9 \%$. S. commune submerged cultivation is a potent alternative to Micromycetes for industrial-scale chitin-glucan complex production.
\end{abstract}

Ke y words: Schizophyllum commune, chitin-glucan, optimized cultivation

List of abbreviations: CGC - chitin-glucan complex, IPA - isopropanol, PDA - potato dextrose agar, rpm - rotations per minute, $\mathrm{vvm}$ - air volume per broth volume per minute, YE - yeast extract

\section{Introduction}

Chitin-glucan complex (CGC) is general name for a wide variety of biological copolymers composed of chitin macromolecules with covalently linked $\beta$-Dglucan chains. The complex naturally occurs in the cellular walls of filamentous fungi, where it forms rigid microfibers that contribute cell wall mechanical strength. CGC can be extracted from fungal mycelium by various physiochemical and enzymatic methods, with the use of inorganic reagents, organic solvents, detergents, etc. (Ivshina, 2007). Traditionally CGC is recovered as an insoluble residue after mycelium successive treatments with alkali and acid. Fungal CGC is considered as an alternative source of chitin/chitosan (Wu et al., 2005; Teslenko and Woewodina, 1996) as well as a potent agent for application in medicine for wound-healing management (Teslenko and Woewodina 1996; Valentova et al., 2009), for improvement of desquamation process and xerosis reduction in diabetic patients (Quatresooz et al., 2009), for reduction of aortic fatty streak accumulation (Berecochea-Lopez et al., 2009), etc.

Traditionally waste mycelium of Aspergillus niger from citric acid production is considered as an indus- trial chitin(chitosan)-glucan complex source. There are several reports on other Micromycetes belonging to genus Ascomycota and Zygomycota utilization for CGC production (Wu et al., 2005; Teslenko and Woewodina 1996). Basidiomycetes have been rarely considered as CGC producers, though they are capable of intensive growth in submerged culture as well. Schizophyllum commune is Basidiomycete used for $\beta$ - $(1,3 ; 1,6)$-Dglucan schizophyllan production. S. commune can be a promising culture for industrial scale CGC production if mycelium growth and CGC content in mycelium is increased and exopolysaccharide synthesis suppressed. The aim of the work was to characterize CGC from S. commune submerged mycelium and to study the possibility of fungal metabolism redirection from exopolysaccharide synthesis to CGC formation.

\section{Experimental}

\section{Materials and Methods}

S. commune strains from different microorganism collections were used: F-795 (Czech Collection of Microorganisms), 11223, 1024, 1025 and 1026 (German

\footnotetext{
* Corresponding author: D. Smirnou, CPN Ltd., Dolní Dobrouč 401, 56102 Dolní Dobrouč, Czech Republic; phone: + (420) 465 519 539; e-mail: smirnou@contipro.cz
} 
Collection of Microorganisms and Cell Cultures), 127 (Collection of Microorganisms CPN Ltd.). The strains were stored on agar slants with PDA at $+4^{\circ} \mathrm{C}$ and subcultured regularly. Prior to experiment the strains were inoculated to Petri dishes that were cultivated for 7 days at $29^{\circ} \mathrm{C}$. $250 \mathrm{ml}$ Erlenmeyer flasks with $100 \mathrm{ml}$ medium (Inoculum I) were inoculated with 10 pieces $0.5 \times 0.5 \mathrm{~cm}$ of mycelium from the Petri dishes and incubated in rotary shakers at $29^{\circ} \mathrm{C}, 200 \mathrm{rpm}$ for 5 days. Inoculum I was then homogenized by T 25 digital Ultra-TURRAX (IKA, Germany) and $50 \mathrm{ml}$ of homogenate were used for inoculation of $1000 \mathrm{ml}$ Erlenmeyer flasks with $500 \mathrm{ml}$ medium. $1000 \mathrm{ml}$ Erlenmeyer flasks were cultivated in rotary shakers at $29^{\circ} \mathrm{C}, 200 \mathrm{rpm}$ for 7 days. In case of cultivations in $50 \mathrm{l}$ fermenter $1000 \mathrm{ml}$ Erlenmeyer flasks with $500 \mathrm{ml}$ medium were cultivated for 3 days and then used as seed culture for fermenter inoculation (5\% amount of inoculum). Fermenters with working volume 0.31 were inoculated with $20 \mathrm{ml}$ of homogenized Inoculum I and cultivation lasted 4 days.

Medium for the seed cultures and production cultivations contained (in g/l): 35 - sucrose, 3 - YE, $2.5-\mathrm{Na}_{2} \mathrm{HPO}_{4}{ }^{\star} 12 \mathrm{H}_{2} \mathrm{O}, 0.5-\mathrm{MgSO}_{4}{ }^{\star} 7 \mathrm{H}_{2} \mathrm{O}$, initial $\mathrm{pH}$ 5.5, unless otherwise specified. Effects of nutrient medium composition and $\mathrm{pH}$ were studied in $1000 \mathrm{ml}$ Erlenmeyer flasks with $500 \mathrm{ml}$ medium. Medium pH was adjusted by $\mathrm{NaOH}$ or $\mathrm{HCl}$ prior to sterilization. Influence of aeration was studied in Sixfors fermenters (INFORS AG, Switzerland) with working volume 0.31 . The cultivation conditions were as follows: temperature $29^{\circ} \mathrm{C}$, agitation $150 \mathrm{rpm}$, aeration $0.5-2.0 \mathrm{vvm}$. Effect of cultivation time was studied in fermenter (INFORS AG, Switzerland) with working volume 501 under the following conditions: temperature $29^{\circ} \mathrm{C}$; aeration $2 \mathrm{vvm}$; agitation $150 \mathrm{rpm}$. Cultivation medium (in g/l): 35 - sucrose, $4-\mathrm{YE}, 2.5-\mathrm{Na}_{2} \mathrm{HPO}_{4}{ }^{\star} 12 \mathrm{H}_{2} \mathrm{O}$, $0.5-\mathrm{MgSO}_{4}{ }^{\star} 7 \mathrm{H}_{2} \mathrm{O}, \mathrm{pH} 6.5$.

Mycelium and schizophyllan yields were measured as follows: $500 \mathrm{ml}$ of cultural broth were centrifuged $\left(10000 \times \mathrm{g}, 25^{\circ} \mathrm{C}, 20 \mathrm{~min}\right)$, supernatant was collected and used for schizophyllan precipitation. Sediment (mycelium) was resuspended in $250 \mathrm{ml}$ of demineralised water, centrifuged again and supernatant was discarded. The process of mycelium washing was repeated 2 more times. The mycelium was placed into a Petri dish, freeze-dried in Heto PowerDry PL 3000 freeze dryer (Thermo Scientific, USA) to constant weight, and mycelium yield in grams of dry mycelium per 1 liter of cultural broth was calculated. Schizophyllan was precipitated from supernatant with triple amount of IPA, dried under $60^{\circ} \mathrm{C}$ for 24 hours, weighted and schizophyllan yield in grams of dry polysaccharide per 1 liter of supernatant was calculated. CGC amount in mycelium was determined as follows: $2 \mathrm{~g}$ of freeze-dried mycelium were resuspended in $60 \mathrm{ml}$ of $4.2 \mathrm{M} \mathrm{NaOH}$.
The mixture was heated to $90^{\circ} \mathrm{C}$ and incubated under this temperature for 3 hours under constant mixing. The mixture was then centrifuged $\left(10000 \times \mathrm{g}, 25^{\circ} \mathrm{C}\right.$, $10 \mathrm{~min}$ ), the supernatant was discarded and sediment was resuspended in $300 \mathrm{ml}$ of demineralised water by Ultra-Turrax T25 Digital (IKA, Germany) and centrifuged again. The process was repeated until supernatant $\mathrm{pH}$ 7. The sediment was then mixed with $60 \mathrm{ml}$ of $0.25 \mathrm{M} \mathrm{HCl}$, resuspended by Ultra-Turrax T25 Digital (IKA, Germany) and incubated for 2 hours at $50^{\circ} \mathrm{C}$. The resulting CGC was centrifuged $\left(10000 \times \mathrm{g}, 25^{\circ} \mathrm{C}\right.$, $10 \mathrm{~min}$ ), supernatant was discarded, sediment was resuspended in $300 \mathrm{ml}$ of demineralised water by UltraTurrax T25 Digital (IKA, Germany) and centrifuged again. The process was repeated until supernatant $\mathrm{pH} 7$. The CGC was dehydrated by IPA, dried under $60^{\circ} \mathrm{C}$ for 24 hours and weighed. CGC content is presented as mass fraction (\%) in dry mycelium. Residual sucrose in the medium was calculated from glucose that resulted from sucrose degradation by baker's yeast invertase (Sigma, USA). Glucose was measured by L-Glucose assay kit GOD-POD (BioVendor, Czech Republic). $\mathrm{pO}_{2}$ in the cultivation broth was measured by optical probe Hamilton-Visiferm DO 120 (Hamilton, Switzerland).

CGC swelling capacity was measured as follows: 0.5 grams of sample were placed into spherical container $45 \mathrm{~mm}$ diameter made of wire screen. The container was deep into water for $40 \mathrm{sec}$. to let the substance swell. Then the container was removed from the water, left for $30 \mathrm{sec}$. to drain and weighed. Swelling capacity ( $\mathrm{g}$ of water/1 $\mathrm{g}$ of sample) was calculated as follows: (weight of container with swelled sample - weight of wet container -0.5$)^{\star} 2$.

Hydrogen bromide titrimetric analysis was conducted by modified method described by Khan et al. (2002) with utilization of $500 \mathrm{mg}$ CGC suspended in $100 \mathrm{ml} 0.2 \mathrm{M} \mathrm{HBr}$. Elementary analyses were made on FISONS EA-1108 CHN elemental analyzer (Italy). Electron-scanning microscope image was made by Tescan VEGA II LSU electron microscope (Tescan USA Inc.) under the following conditions: high voltage $5 \mathrm{kV}$, working distance $4.4 \mathrm{~mm}$, magnification 5000, display mode secondary electrons, high vacuum, room temperature. A15 nm layer of gold particles was applied on the sample by SC7620 Mini Sputter Coater (Quorum Technologies, UK). All experiments were repeated at least 3 times. The data is presented as value \pm standard deviation.

\section{Results and Discussion}

Mycelium growth and CGC production by submerged culture of six S. commune strains was studied. Cultivation lasted 7 days, corresponding to late 
Table I

Mycelium yield, CGC content in mycelium, CGC and schizophyllan production by different $S$. commune strains

\begin{tabular}{|l|c|c|c|c|}
\hline $\begin{array}{c}\text { S. commune } \\
\text { strain }\end{array}$ & $\begin{array}{c}\text { Mycelium } \\
\text { yield } \\
\text { g/l }\end{array}$ & $\begin{array}{c}\text { CGC in } \\
\text { mycelium } \\
\%\end{array}$ & $\begin{array}{c}\text { CGC } \\
\text { production } \\
\text { g/l }\end{array}$ & $\begin{array}{c}\text { Schizophyllan } \\
\text { production } \\
\text { g/l }\end{array}$ \\
\hline F-795 & $6.0 \pm 0.2$ & $15.2 \pm 0.4$ & $0.9 \pm 0.1$ & $2.3 \pm 0.5$ \\
\hline 11223 & $11.0 \pm 0.4$ & $17.4 \pm 0.2$ & $1.9 \pm 0.2$ & $1.7 \pm 0.2$ \\
\hline 1024 & $8.5 \pm 0.1$ & $16.1 \pm 0.1$ & $1.4 \pm 0.3$ & $0.7 \pm 0.1$ \\
\hline 1025 & $8.6 \pm 0.5$ & $17.1 \pm 0.1$ & $1.5 \pm 0.2$ & $0.7 \pm 0.1$ \\
\hline 1026 & $12.3 \pm 0.3$ & $20.3 \pm 0.3$ & $2.5 \pm 0.2$ & $1.2 \pm 0.3$ \\
\hline 127 & $11.4 \pm 0.7$ & $30.2 \pm 0.2$ & $3.4 \pm 0.4$ & $0.5 \pm 0.1$ \\
\hline
\end{tabular}

stationary growth phase. S. commune mycelium yield varied between $6.0 \pm 0.2 \mathrm{~g} / \mathrm{l}$ and $12.3 \pm 0.3 \mathrm{~g} / \mathrm{l}$ (Table I). For comparison, mycelium yields of chitin producers A. niger and Mucor rouxii are reported about $7 \mathrm{~g} / \mathrm{l}$ and $5 \mathrm{~g} / \mathrm{l}$ respectively (Wu et al., 2005; Tan et al., 1996). CGC content in mycelium of different S. commune strains ranged within $15.2 \pm 0.4 \%$ and $30.2 \pm 0.2 \%$ and was similar to that reported for Aspergillus and Mucor (Wu et al., 2005, Arcidiacono and Kaplan 1992, Muzzarelli et al., 1980). CGC production by S. commune reached $3.4 \pm 0.4 \mathrm{~g} / \mathrm{l}$ that is superior to many reported production values of Micromycetes.

The microstructure and chemical composition of CGC from S. commune mycelium (Strain 127) were analyzed. The copolymer was a cotton-like substance white to creamy in color without odor. Electron-scanning microscopy showed that even after harsh extraction that removes alkali soluble cell wall polysaccharides, CGC from S. commune was composed of microfibers with diameter 1-2 $\mu \mathrm{m}$, similar to fungal hypha (Fig. 1). Highly developed microstructure determined remarkable swelling capacity of the complex that was 18 grams of water per 1 gram of CGC and was comparable with that measured for cotton wool $(35 \mathrm{~g} / \mathrm{l})$. This characteristic makes CGC from S. commune a valuable product for application in bandages.

Elementary analyses of the complex showed nitrogen content $1.22 \pm 0.10 \%$, carbon $42.20 \pm 0.24 \%$ and hydrogen $6.61 \pm 0.15 \%$. Glucosamine in the complex comprised $4.5 \pm 0.4 \%$. When these two analyses were combined, the composition of CGC from S. commune can be assumed as follows: $16.6 \%$ chitin and $83.4 \%$ of glucan with chitin deacetylation degree $27 \%$. Although, chitin portion in S.commune CGC is lower than in A. niger, where chitin content is reported to be about 30\% (Wu et al., 2005; Machova et al., 1999), utilization of $S$. commune for chitin production is promising due to high CGC yield.

Fungal mycelium separation from cultivation medium is an essential technological step in CGC production. From this point, filtration of S. commune cultural broth is a rather complicated process due to exopolysaccharide content. The possibilities of CGC production increase together with exopolysaccharide synthesis suppression by variation of cultivation technique were studied. The study was conducted on S. commune F-795.

CGC accumulation by fungi can be effected by nitrogen source in nutrient medium. Sousa et al. (2003) reported that when Mucor circinelloides was cultivated in synthetic medium with L-asparagine as single nitrogen source, chitin content in mycelium depended upon amino acid concentration. There was studied effect of yeast extract (YE) in the medium on CGC production by $S$. commune. The amount of YE was varied from $2 \mathrm{~g} / 1$ up to $5 \mathrm{~g} / \mathrm{l}$ and CGC content in mycelium, mycelium yield and schizophyllan synthesis were measured. It was found, that CGC content in S. commune mycelium is little affected by YE, and it varied in the range of $15.4 \pm 0.3 \%$ under all studied YE concentrations. Increase of YE content from 2 to $4 \mathrm{~g} / \mathrm{l}$ increased mycelia biomass production more than 1.5 times (Fig. 2). Further supplementation of the medium with YE increased mycelium growth only slightly. As distinct from mycelium, schizophyllan synthesis was suppressed by YE concentrations over $4 \mathrm{~g} / \mathrm{l}$ (Fig. 2).

Amorim et al. (2001) reported medium $\mathrm{pH}$ as a regulating agent for chitosan production by Mucor racemosus and Cunninghamella elegans. The effect can be due to chitin deacetylase activity modification. It can be expected that medium $\mathrm{pH}$ may effect activity of enzymes, involved in S.commune CGC formation as well. CGC production by S.commune in medium with different initial $\mathrm{pH}$ was studied. Again, CGC

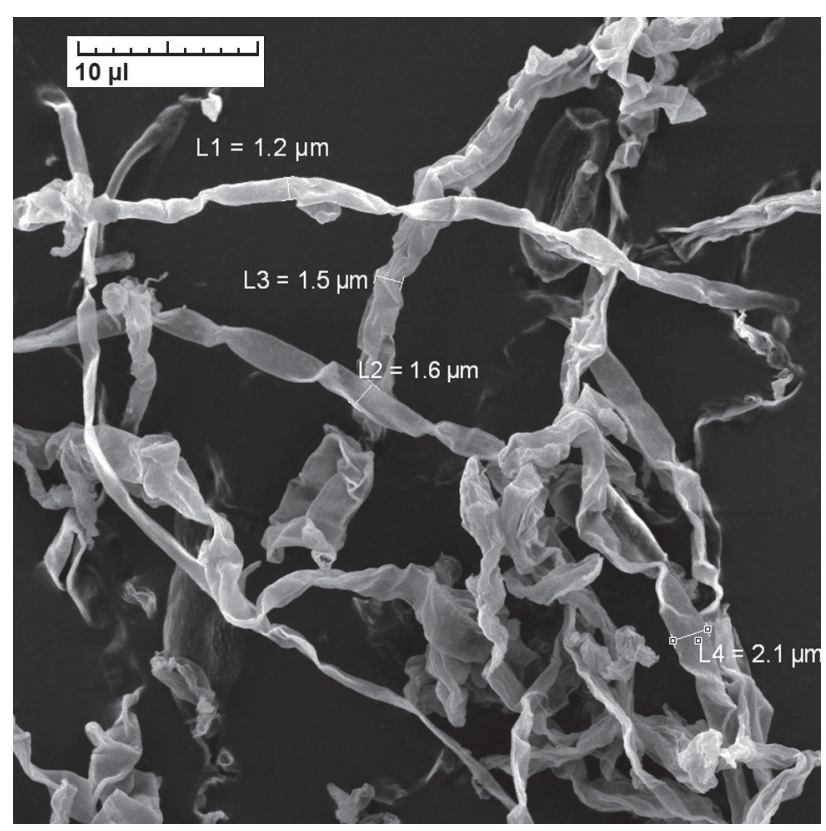

Fig. 1. Electron-scanning microscope image of CGC from S. commune submerged mycelium (High voltage $5 \mathrm{kV}$, working distance $4.4 \mathrm{~mm}$, magnification $\times 5000$ ). 


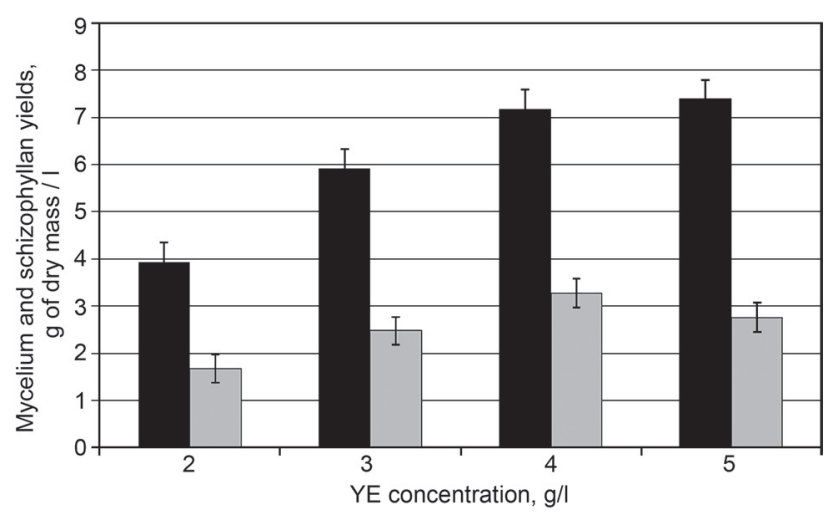

Fig. 2. Effect of YE in nutrient medium on mycelium yield ( $(\bullet)$ g/l and schizophyllan production $(\nabla) \mathrm{g} / \mathrm{l}$ by $S$. commune.

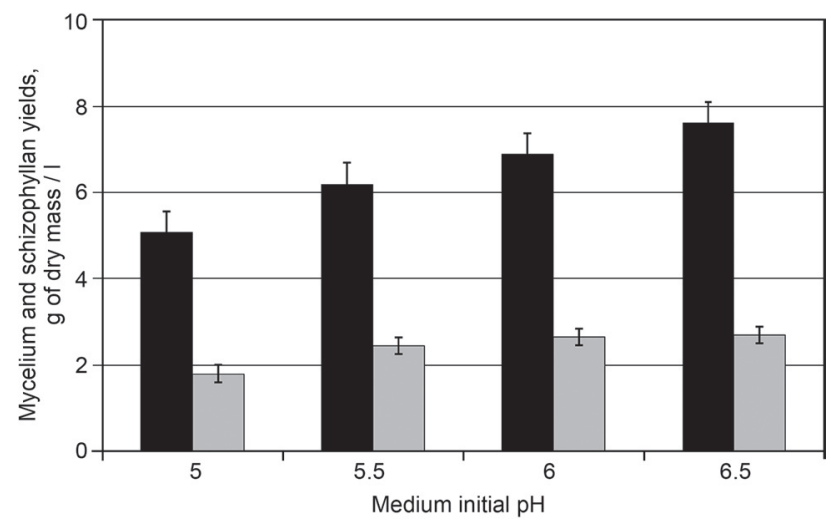

Fig. 3. Effect of initial medium $\mathrm{pH}$ on mycelium yield (- $) \mathrm{g} / \mathrm{l}$ and schizophyllan production $(\varpi) \mathrm{g} / \mathrm{l}$ by $S$. commune.

content in mycelium was not significantly affected by $\mathrm{pH}$ and varied in the range of $15.1 \pm 0.4 \%$. Mycelium yield reached highest values at medium initial $\mathrm{pH} 6.5$ (Fig. 3). Medium neutralization from $\mathrm{pH} 5$ to $\mathrm{pH} 6$ increased schizophyllan production 1.5 times. Further increase of medium $\mathrm{pH}$ left schizophyllan synthesis practically unchanged.

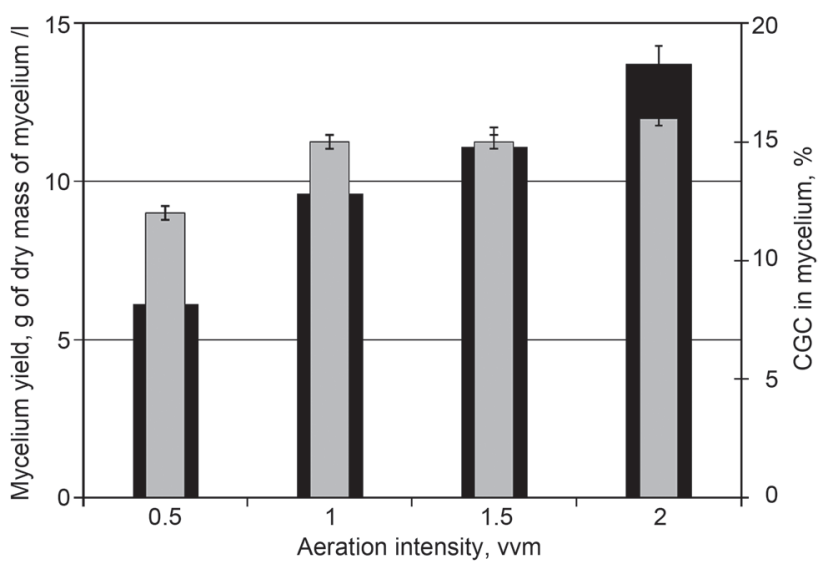

Fig. 4. Effect of aeration intensity on S. commune mycelium yield $(-) \mathrm{g} / \mathrm{l}$, and CGC content in mycelium ( $\bullet$ ) \%.

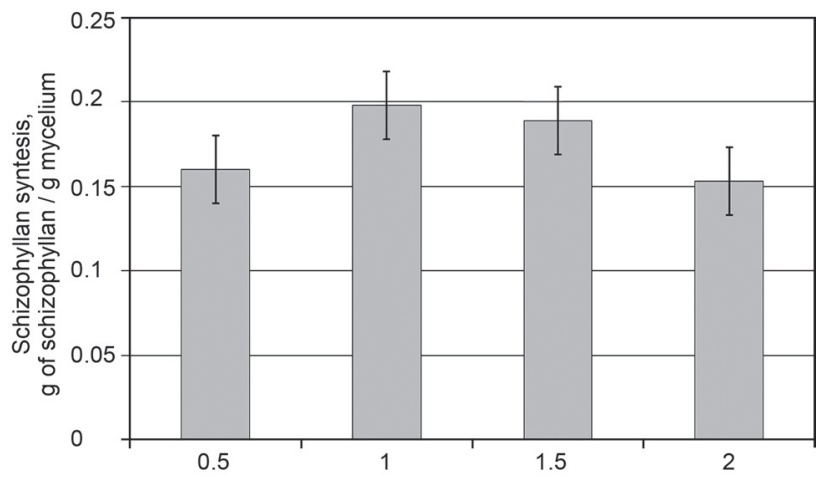

Fig. 5. Effect of aeration intensity on S. commune schizophyllan synthesis, grams of schizophyllan per gram of mycelium in the cultural broth.

It is reported (Aguilar-Uscanga et al., 2003) that aeration intensity effects cell walls formation in fungi. In agreement with this, our study showed very significant changes in CGC production by S. commune during cultivation under different aeration rates. CGC content in mycelium rose from $12.4 \pm 0.3 \%$ to $15.5 \pm 0.3 \%$ when aeration increased to $1 \mathrm{vvm}$ (Fig. 4). Further

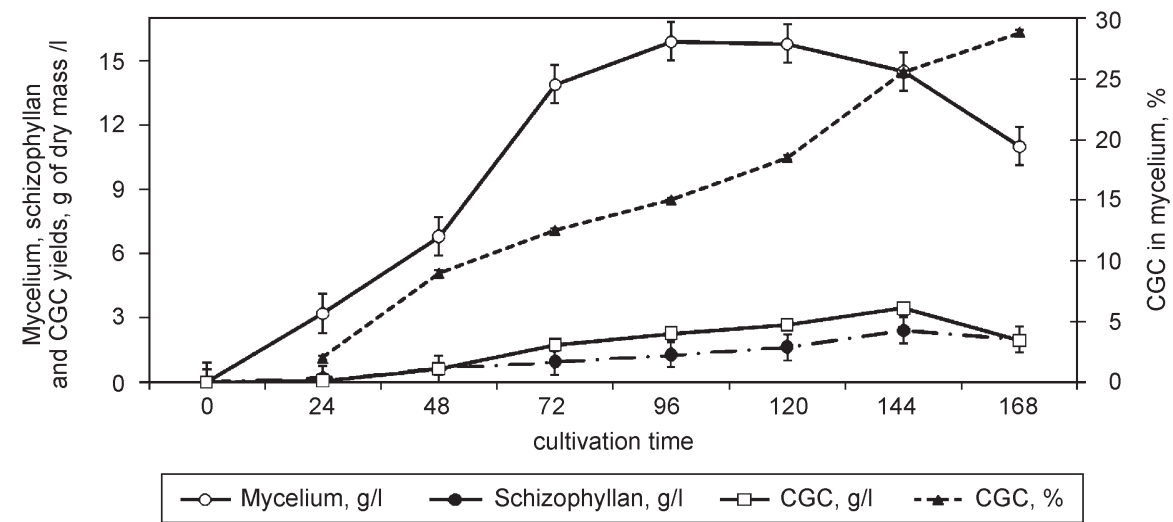

Fig. 6. Change of mycelium yield (g/l), CGC content in mycelium (\%), CGC and schizophyllan production $(\mathrm{g} / \mathrm{l})$ during S. commune cultivation. 


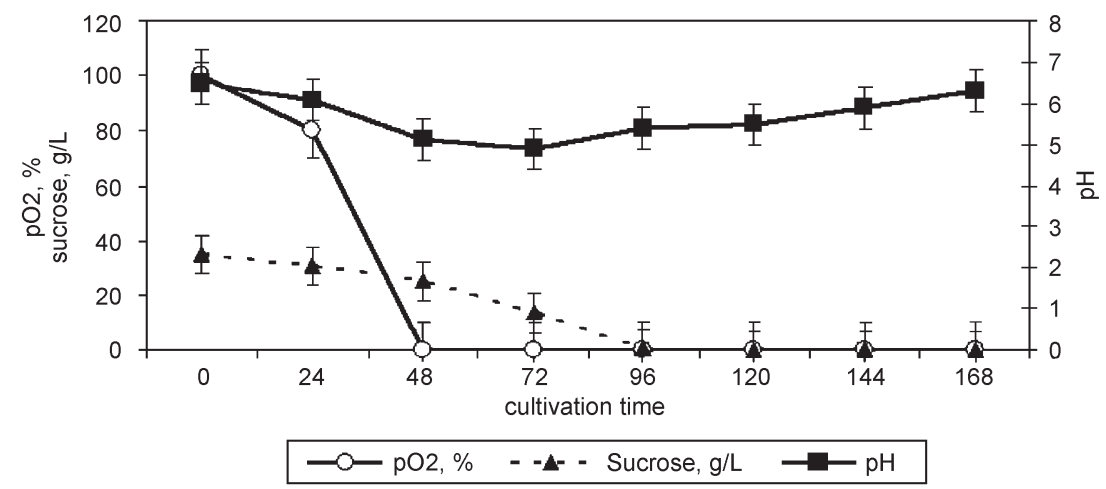

Fig. 7. Change of medium $\mathrm{pH}, \mathrm{pO}_{2}(\%)$ and sucrose content in medium (g/l) during S. commune cultivation.

aeration increase up to $2 \mathrm{vvm}$ increased CGC content to $16.3 \pm 0.3 \%$ only. Mycelium yield increased more than 2 times with increase of aeration from $0.5 \mathrm{vvm}$ to $2 \mathrm{vvm}$ and reached the maximum value of $13.7 \pm 0.6 \mathrm{~g} / \mathrm{l}$ (Fig. 4). From the data above, there was calculated maximal CGC production of $2.2 \pm 0.2 \mathrm{~g} / 1$ under $2 \mathrm{vvm}$ aeration.

When the amount of schizophyllan was related to mycelium yield, it was found that the most intensive exopolysaccharide synthesis takes place at aeration of $1 \mathrm{vvm}$ (Fig. 5). These indicate that aeration intensity can be used as the key regulator for redirection of S. commune metabolism from schizophyllan synthesis to CGC accumulation.

Cultivation conditions that favored high CGC production (YE $4 \mathrm{~g} / \mathrm{l}, \mathrm{pH} 6.5$, aeration $2 \mathrm{vvm}$ ) were combined and effect of cultivation time on CGC and schizophyllan accumulation was studied in fermenter with 501 working volume. The culture reached stationary growth phase in 96 hours, the highest mycelium yield of $15.9 \pm 0.9 \mathrm{~g} / \mathrm{l}$ was recorded at that cultivation time as well (Fig. 6). Amount of CGC in mycelium increased during all cultivation and reached maximum value of $28.1 \pm 0.2 \%$ in 168 hours. The highest CGC production of $3.5 \pm 0.3 \mathrm{~g} / 1$ was recorded in 144 hours of cultivation. The amount of schizophyllan in medium increased until $144 \mathrm{~h}$ of cultivation when it reached $2.4 \pm 0.6 \mathrm{~g} / \mathrm{l}$, whereupon it started to decrease (Fig. 6).

S. commune acidified medium to $\mathrm{pH} 4.9$ in first 72 hours, however then medium $\mathrm{pH}$ started to increase and reached 6.3 at the end of cultivation (Fig. 7). All sucrose was consumed within the first 96 hours. $\mathrm{pO}_{2}$ probe indicated $0 \%$ medium oxygen saturation beginning from 48 hours of cultivation (Fig. 7).

By means of cultivation conditions optimisation CGC production by S. commune was increased more than 3.8 times. CGC content in mycelium was little sensitive to medium composition, but was increased by aeration intensification and cultivation time prolongation. Mycelium yield was increased by adjustment of YE content in the medium, medium initial $\mathrm{pH}$ and aeration intensity. Redirection of fungal metabolism from schizophyllan synthesis to CGC accumulation was achieved most efficiently by aeration intensity increase. The study showed the potential of S.commune submerged cultivation for industrial-scale CGC production. CGC from S. commune can find application in medicine and chitin/chitosan production as an alternative to CGC from Micromycetes.

\section{Acknowledgement}

We thank prof. Ing. Radim Hrdina (Institute of Organic Chemistry and Technology, University of Pardubice, Czech Republic) for elementary analyses. This work was supported by a grant from EU funds and national budget of the Czech Republic under project Nr. FR-TI 1/151 "New Wound Dressings Based On Micro- and Nano- Carriers" covered by TIP platform.

\section{Literature}

Aguilar-Uscanga B. and J.M. Francois. 2003. A study of the yeast cell wall composition and structure in response to growth conditions and mode of cultivation. Lett. Appl. Microbiol. 37: 268-274.

Amorim R.V.S., W. de Souza, K. Fukushima and G.M. CamposTakaki. 2001. Faster chitosan production by Mucoralean strains in submerged culture. Braz. J. Microbiol. 32: 20-23.

Arcidiacono S. and D.L. Kaplan. 1992. Molecular weight distribution of chitosan isolated from Mucor rouxii under different culture and processing conditions. Biotechnol. Bioeng. 39: 281-286.

Berecochea-Lopez A., K. Decordé, E. Ventura, M. Godard, A. Bornet, P.L. Teissèdre, J.P. Cristol and J.M. Rouane. 2009. Fungal chitin-glucan from Aspergillus niger efficiently reduces aortic fatty streak accumulation in the high-fat fed hamster, an animal model of nutritionally induced atherosclerosis. J. Agric. Food Chem. 57: 1093-1098.

Ivshin V.P., S.D. Artamonova, T.N. Ivshina and F.F. Sharnina. 2007. Methods for isolation of chitin-glucan complexes from higher fungi native biomass. Polym. Sci. 49: 305-310.

Khan T.A., K.K. Peh and H.S. Ch'ng. 2002. Reporting degree of deacetylation values of chitosan: the influence of analytical methods. J. Pharm. Pharmaceut. Sci. 5: 205-212.

Machova E., G. Kogan, D. Chorvatovicova and J. Sandula. 1999. Ultrasonic depolymerization of the chitin-glucan complex from Aspergillus niger and antimutagenic activity of its product. Ultrason. Sonochem. 6: 111-114. 
Muzzarelli R.A.A., F. Tanfani and G. Scarpini. 1980. Chelating, filmforming, and coagulating ability of the chitosan-glucan complex from Aspergillus niger industrial wastes. Biotechnol. Bioeng. 22: 885-896.

Quatresooz P., C. Piérard-Franchimont, G. Szepetiuk, C. Devillers and G.E. Piérard. 2009. Fungal chitin-glucan scaffold for managing diabetic xerosis of the feet in menopausal women. Expert. Opin. Pharmacother. 10: 2221-2229.

Sousa A.V., N.B. de Barros, K. Fukushima and T.G.M. Campos. 2003. Effect of medium components and time of cultivation on chitin production by Mucor circinelloides (Mucor javanicus IFO 4570) - a factorial study. Rev. Iberoam. Micol. 20: 149-53.
Tan C.S., K.T. Tan, M.S. Wong and E. Khor. 1996. Chitosan yield of zygomycetes at their optimum harvesting time. Carbohydr. Polym. 30: $239-242$.

Teslenko A. and I. Woewodina. 1996. Process for producing chitosan-glucan complexes, compounds producible therefrom and their use. United States patent US 6333399 B1.

Valentová Z., H. Bilerová, R. Suláková and V. Velebný. 2009. Preparation for wound healing and prevention of bandage adhesion to the wound, containing chitosan-glucan. Patent WO/2009/043319. Wu T., S. Zivanovic, F.A. Draughon, W.S. Conway and C.F. Sams. 2005. Physicochemical Properties and Bioactivity of Fungal Chitin and Chitosan. J. Agric. Food Chem. 53: 3888-3894. 